\title{
First Results with a Virtual Platform for the Renewable Energy Technology Courses
}

\section{Dr. Radian G Belu, Drexel University (Tech.)}

Dr. Radian Belu is Assistant Professor within the Engineering Technology (ET) program - Drexel University, Philadelphia, USA. He is holding the second position as Research Assistant Professor at Desert Research Institute - Renewable Energy Center, Reno, Nevada. Before joining to the Drexel University Dr. Belu hold faculty and research positions at universities and research institutes in Romania, Canada and United States. He also worked for several years in industry as a project manager and senior consultant. He has taught and developed undergraduate and graduate courses in electronics, power systems, control and power electronics, electric machines, instrumentation, radar and remote sensing, numerical methods and data analysis, space and atmosphere physics, and physics. His research interests included power system stability, control and protection, renewable energy system analysis, assessment and design, power electronics and electric machines for wind energy conversion, radar and remote sensing, wave and turbulence simulation, measurement and modeling, numerical modeling, electromagnetic compatibility and engineering education. During his career Dr. Belu published several papers in referred journals and in conference proceedings in his areas of the research interests. He has also been PI or co-PI for various research projects United States and abroad in power systems analysis and protection, load and energy demand forecasting and analysis, renewable energy analysis, assessment and design, turbulence and wave propagation, radar and remote sensing, instrumentation, atmosphere physics, electromagnetic compatibility, and engineering education. 


\title{
First Results with a Virtual Platform for the Renewable Energy Technology Courses
}

\begin{abstract}
In the modern world, where everything changes at an extremely fast rate, a constant and everyday updating of knowledge is imperative. The recent growth of renewable energy usage, as well as the development of new and effective tools for monitoring, operation and control require to the training of workforce in the field of renewable energy systems. Nowadays all energy companies use renewable energy sources applications. As those technologies change quickly, instructors, engineers and researchers need to keep this fast pace and update their knowledge and keep up with innovative concepts. Since traditional learning methods are time consuming and sometimes impractical, learning through the Internet seems maybe the only effective and feasible solution. There is a need for new learning tools and practical experiences which can now be met by new teaching methods, such as virtual learning. In recent years due to the Internet advances, and the fast development of computer technologies, E-Learning has been well accepted in many different education areas and at many universities. Computing and communication technology have had a significant impact on engineering education, improving online, distance, and collaborative learning, as well as the use of the virtual and remote experiments, laboratories and simulations. On the other hand, the renewable energy technology has a great development rate and it is mandatory also for professionals, engineers, and technicians to be informed about their domains' new features. Distance-learning programs and remote laboratories are ideal for them to update their knowledge and skills. These tools developed are mainly designed as a base for a virtual laboratory that can be used for the study of renewable energy system parameters, representing, by didactical point of view, a handful way for students to study the phenomenology and also a training tool for specialists, technicians and engineers in the renewable energy technologies. This paper presents a virtual platform conceived for the study of the renewable energy sources and energy conversion systems. Besides of the study of the generated renewable energy or energy conversion system parameters, the monitoring using virtual instrumentation is implemented. The virtual platform realized using the LabVIEW, Interactive Data Language, Maple and MATLAB/Simulink environments. It will provide students with enhanced tools of study, virtual experiments on renewable energy sources, energy conversion and hybrid power systems. The proposed system provides the learner with information about the most important functions, principles and operational problems of each of the renewable energy sources and energy systems included.
\end{abstract}

\section{Introduction}

Environmental concerns, the ever-increasing needs for power generation, depletion of the fossil fuel reserves, and steady progress in power deregulation have created increased interest in environmentally conscious distributed power generation. Of particular interest are renewable energy systems (RES) such as: wind, solar/photovoltaic (PV), geothermal, wave and tide energy, and fuel cells (FC), with zero (or near zero) pollutant emissions. These power generation systems can be used in stand-alone configuration or connected to the grid. This unprecedented growth of renewable energy usage as a result of installation of more and more generating units involves 
preoccupations concerning their monitoring, operation and maintenance, leading to the conceiving of new and effective tools for monitoring and control of these systems, as well as to the training of specialists in the RES fields. Given this rapid progress in renewable energy utilization, there is a great need for trained professionals with adequate knowledge in this area to be able to plan, design and operate RES systems, and perform analytic evaluation of their impact on power systems to which they are connected ${ }^{1-5}$. On the other hand, electric power systems, electric transmission and distribution systems are undergoing rapid changes due to deregulation, the penetration of dispersed and distributed energy resources (DER), renewable energy generation and power electronics technologies, and the adoption of efficient computation, communications and control mechanisms. Due to these facts together with the interest of keeping students abreast of the current scientific and technological developments and trends, we believed that it was important and timely to develop upper-level undergraduate courses and laboratories on renewable energy systems, and to include renewable energy projects in senior project design courses in our ET program. There is a well-documented demand and need in offering program study, courses and training in the areas of renewable energy ${ }^{5-10}$. Future engineers must be taught to be creative, flexible and imaginative. Future engineering curriculum should be built around developing and increasing skills and technical knowledge. The topic of renewable energy is not only relevant to a multitude of issues today, it is also an effective vehicle for developing instruction that applies across a variety of content disciplines and academic standards.

Equipping engineering students with the skills and knowledge required to be successful engineers in the 21st century is one of the primary objectives of university educators. Enabling students to practice self-directed learning, to find solutions to design problems that are sustainable, and helping them to recognize that they are part of a global community are just a few of our educational goals. Engineering and engineering technology programs must offer a relevant and validated curriculum that prepares students for post-graduation success. Courses that cover traditional subject matter in mathematics, sciences, economics and other related topics provide the foundation of knowledge upon which specific skill sets are added. However, it is critical for engineering education to transition from theoretical work in the classroom towards experiential learning with applications of technology and design. In the modern world, where everything changes at an extremely fast rate, a constant and everyday updating of knowledge is necessary. Nowadays all energy companies use plenty of the advanced technologies such as RES, control or power electronics. As these technologies change quickly, and the engineers, technologists and technicians do not always have enough time to attend new courses in order to improve their knowledge and keep up with innovative concepts, learning through the Internet seems maybe the only effective and feasible solution. In our industrial society it is quite difficult for specialized staff to quickly and thoroughly learn and become integrated into the new modern manufacturing process. There is a need for new learning tools and practical experiences which can now be met by new teaching methods, such as virtual learning. In recent years due to the Internet and computing technology advances, growing interest and the fast development of computer technologies, E-Learning has been well accepted at many different education areas in many universities around the world. Furthermore, educational institutions should offer long-distance learning to meet the needs of a knowledge-based society ${ }^{1-3}$. Simulations can be used to illustrate difficult phenomena in the power system and RES technologies. With this, the explanation of the phenomena can be given in an open and clear way, not only by text and picture. Furthermore, the student has the possibility to immediately conduct research by changing some parameters ${ }^{11-17}$. 
During recent years the traditional education system has witnessed dramatic changes. The reasons for this lay in the global orientation of the world economy, strong competition and the change of the social structure. Information and communication technologies (ICTs) have rapid development. They open up new horizons for progress. Modern information and communication technologies are transforming the way people learn. The new information techniques make it possible to optimize the requirements of the modern society, so a lot of institutions for higher education throughout the world are developing and offering new teaching methods to the students, as so called virtual teaching. E-Learning, supported by the fast development of computer technology as well as by the processing of the Internet in the 1990`s, manages a very good acceptance in different educational areas at all universities across the globe. E-Learning also provides new possibilities for personalized learning in the workplace, in the classroom or at home. E-learning can be defined as instructional content or learning experiences aiming to learn and increase visitors' knowledge and skills in order to be more productive which gives a boost to their careers. E-learning has the potential to attract anyone who is eager to remain close to new products and processes ${ }^{10-18,23-32}$.

One of the main purposes of our work is to develop a system usable for monitoring, technical study on-site and for on-line distance learning. The main goal of the system is to provide access to renewable energy generation units, primarily for monitoring or for control of primary energy source parameters when used for study. All these are including the permanent access to current data but also to the recorded ones too. When a RES unit is used for experimental and learning purposes the system is designed to provide a way to a good understanding of physical phenomena and of measured parameters related to renewable energy conversion systems. The main goal of this project was to develop, implement and test a unified laboratory (consisting of a set of five actual device-based emulators and simulators of main renewable energy sources) and an e-Learning support platform consisting of six learning/instructional modules that can be used for renewable energy and energy-related courses. A dynamic, user-friendly e-Learning support platform and a scalable experimental laboratory that will empower the interested users to browse along the technological development in renewable energy technologies and sustainability and to conduct experimental work in these areas was developed during this project. The virtual and actual experiments and modules, developed during the project allow to our students to explore the principles, characteristics and operation of various renewable energy sources, storage devices, and energy conversion systems. The new developed learning materials allow our undergraduate students to "see and feel" the emerging renewable energy technology through interactive real and/or virtual laboratory experiments.

\section{Course Contents, Laboratory Platform Structure and Realization}

Our upper-level undergraduate course on renewable energy and power systems was first offered in Spring 2008-2009 quarter, and it was offered for each academic year subsequently since then. The renewable energy course and power system is divided into ten modules. Each module can be completed within three-hour lecture sessions. Due to the diverse and interdisciplinary subjects needed to be covered, the following reference texts are used and recommended to the students. Based on these and additional references the following course syllabus was developed ${ }^{19-23}$. It focuses on wind energy, wind power systems and solar/photovoltaic (PV) energy generation. To a lesser extend it focuses on other renewable energy sources and related technologies. Wind and 
solar energy conversion system make up about $80 \%$ of the course since wind and solar energy represent the fastest growing areas of renewable energy in the past decade. Therefore the key areas that the course focuses are the wind and solar energy sources and the related technologies. The teaching modules of this course consist of the following topics each of them presenting a special type of renewable energy and dispersed generations. The outline of the course includes (ten 3-hour lectures):

1. Basic principles of energy generation

2. Introduction to renewable energy systems

3. Electric machines Basics; Electric machines for renewable

4. Solar energy fundamentals

5. Photovoltaic energy production; Photovoltaic systems

6. Wind energy resource characteristics

7. Wind energy conversion systems: aerodynamic and electric aspects

8. Wind energy modeling aspects

9. Fuel cell systems

10. Distributed generation and power quality

The laboratory exercise will include:

1. Wind Turbine Experiments

2. PV/Solar Systems

3. Solar-Thermal System

4. Fuel Cells Unit

5. Batteries

The experiments focus on the system characteristics, principles, control and power electronics. Since this course deals mainly with the analysis and the components of the wind and solar energy conversion systems, as well the analysis of integration and interconnection to the power system grid, the desired prerequisites include a course in energy conversion, electric machines and corequisites a course in power electronics and power system analysis. Students are expected to be well around in general renewable energy issues, electric machines and energy conversion technologies. They are expected to be particularly skillful in analyzing and solving wind and solar power systems and related problems.

\section{Virtual Laboratory Issues}

The most common modern classroom environment is the multimedia classroom which includes: projectors and large screens, object display platform, DVD player and computers. Among them, computer is increasingly becoming the center of the multimedia classrooms. Due to the lively features of having the image of specific and providing activities that students can personally involve in, modern curriculum resources provide students with a wide range of information stimulation and arouse students' sense and interests to participate in activities which seems like a real scene so that students can increase their knowledge pleasantly and develop their own capacity, which cannot be replaced by the traditional teaching. Virtual lab is an online virtual experiment system which is based on web technology and virtual reality technology. It is the digitization and virtualization of laboratories on campus. Virtual lab consists of a virtual 
laboratory bench, a virtual equipment cabinet and the web-based software for laboratory management. Virtual lab provides a bran-new learning and training environment for experimental courses ${ }^{23-36}$. The virtual laboratory bench is similar with the real laboratory settings. Students can easy configure, connect, debug and operate the virtual experimental equipment. Teachers can use the equipment in the virtual equipment cabinets to set up any reasonable typical experiment or experiment cases. This is an important feature that is different from general experimental courseware. The virtual experiments provide the teachers and students a more direct and convenient simulation experiment environment, without the constraint of complex and inefficient of the physical teaching process by using simulation technology.

The authors considered the use of this approach from the point of view of educators and learners. The following advantages of teaching within simulation and virtual approaches were determined for the educators:

- Tutors could contact any students privately by voice-enabled chat and/or the instant messages;

- Many more experiments were possible using the 3D simulator;

- The approach lends itself easily to the current trend towards student-centered education;

- Less staff effort was required for higher-level teaching activities.

The following disadvantages of teaching within SL were determined for educators:

- Virtual learning needs a permanent Internet connection and good performance from PCs, implying a good level of institutional support;

- The educators may not be sure of the student identities;

- Emotional responses of students cannot be perceived by educators, unlike in a classroom setting.

The following advantages of working within simulation and virtual learning were determined for the students:

- Opportunity for many more learning student-centered learning activities;

- Fun and learning can be combined, so that students are engaged with the topic;

- Students can interact with places or operating equipment which, due to extreme hazard, cannot be seen by them in the real world, such as the inner workings of a substation;

- Physically disabled students can greatly benefit from them;

- Synchronous and asynchronous learning is possible.

The following disadvantages were determined for the students: SL needs a permanent Internet connection and a good performance of PCs which may result in extra financial costs; and if students over-use virtual learning outside learning hours, they may risk becoming socially isolated in real life. In addition to the above, educational and experimental materials are created virtually which are free of cost to both educators and students as opposed to real-life learning environments. Initially, educators should learn how to build, design and write scripts in for a specific virtual learning system, which can be difficult and time consuming process. The virtual classrooms, virtual labs, virtual campus and virtual communities play an essential role in building the virtual educational environment. However, the progress of such technology does not fundamentally change the effect of teaching and learning. The main reason is that they are only a 
mapping for real educational environment. Therefore, it is difficult to go beyond and completely change the existing educational environment. However, with many colleges offering distance education programs in engineering and technology, the demand for truly interactive simulationbased online labs is on the rise. An interactive lab is capable of partially substituting or extending conventional hands-on laboratories. Virtual labs have great potential for facilitating the active learning mode and transforming "e-learning by reading and watching” into a more efficient "learning by doing". They also provide an efficient and effective way of teaching complex and dynamic engineering systems. In this regard, the extraordinary interest in the renewable energy and energy conservation technologies has led to an increased demand for engineering and engineering technology graduates who are not only skilled in installation, maintenance of equipment and controls used in the intelligent infrastructure systems required to generate and supply electricity in commercial and residential applications, but who also understand the fundamental principles underlying the design and operation of alternative systems, smart grid, sensors, etc. However, incorporation of such learning processes and the state-of-the-art technological tools and equipment requires considerable time and financial resources. Keeping curricula and labs current with the rapid change of technology poses another challenge for faculty. Engineering and engineering technology professors can address some of these challenges by using simulation and virtual experiments. 2 In addition to cost savings, simulation offers a number of other advantages:

- $\quad$ Allowing the user to modify system parameters and observe the outcomes without any harmful side effects.

- $\quad$ Eliminating component or equipment faults that affect outcomes.

- $\quad$ Supporting users progress at their own pace in discovery and understanding of concepts and issues.

- $\quad$ Enhancing the presentation of “dry” concepts by integrating theory and practice.

However, simulation is not an universal panacea for the problems of keeping curricula current, as it has some limitations too; for example, the use of software simulations of physical entities, such as electronic circuits, denies the user a chance to physically handle the circuit components or construct the circuit.3 On the other hand, simulation has another major advantage in that a simulation is task- and learner-neutral; it models an object/system construction and operation or learning situation. Within simulation functionality, there are no restrictions on the student's actions. Thus, the advantages of simulation outnumber its disadvantages. In the areas of electrical and electronics engineering and technology and manufacturing technology, there are numerous uses for simulation, starting from simulation of electric circuits to complex tasks such as electromagnetic fields, networking, computer circuits, game programming, electron flow in semiconductors, and manufacturing process control and monitoring.

\section{Virtual Platform, Structure and Implementation}

There are clear differences between a simulation, virtual experiment, and virtual laboratory. A simulation is task- and learner-neutral, i.e., it models a process, an object's or system's construction and operation, or a learning situation. Within simulation functionality, there are no restrictions on the user's actions. In contrast with a simulation, a virtual experiment is focused on a particular task. In addition to simulation, the virtual experiment includes specific learning 
objectives, scenario/assignment worksheet, assessment tool, and, most importantly, step-by-step instructions for students. Virtual experiments may also include optional auxiliary simulations, prerequisites, excerpts from interactive lessons and technical manuals, quizzes, and online reference resources. The student is expected to follow a set of step-by-step instructions to accomplish a particular educational assignment, whereas the virtual labs incorporate several virtual experiments that can share simulations and supplementary e-learning resources. Our eLearning platform represents a set of tools and programs, which manage the interaction between the training system users (students, tutors and administrators) and the central server. The two principal features of the e-learning platform are the delivery of information and data, in electronic format as didactical units e.g. courses, lessons and checking of the training results ${ }^{2}$. With this server-client approach our platform remains an open system for implementing new information in the future. The information - study area is adaptive to the user and the teaching contents are listed in a tree structure, which enables easier orientation of the student during the studying. The control and guidance of the students through the teaching contents has been realized using Petri Networks ${ }^{24,30-32}$. Each project user is able to log on to the server by simply using browsers e.g. Mozilla, Explorer or Netscape.

Our system can be used for study of theoretical models, but also for study of above parameters' and/or characteristics influence and comparisons to real models. Obviously, when the control function is activated, the studies on real models can be performed, for example in the chase of solar energy conversion systems when the solar radiation is available or by using an artificial source of lighting radiation. The virtual platform for renewable energy was conceived to perform studies using existing data but also data preset by the user. In the case of on-line operation and utilization, data history can be used for the study of available solar radiation, wind speed or other data, appropriate for each renewable energy source are available during different time periods (day, week, season or year). The analysis of recorded data can be performed in off-line study. The available physicals models can be tested in different configurations at different parameters (e.g. solar photovoltaic cells of different parameters in series or parallel connections, wind turbine type and configuration, generator models, power electronics, converters, etc.).

\subsection{System Architecture, Structure and Components}

Figure 1 shows the block diagram of our e-Learning system. The system is structured on 3 components: 1) experimental workstation with a DAQ module; 2) the module for study of theoretical models; and 3) web based application with database. The experimental workstation for the study of the RES is represented by a basic workstation extended with a data acquisition module implemented with a computer equipped with DAQ board. Data obtained from DAQ board are pre-processed and sent to the upper levels of the application by a software component developed in LabVIEW, MATLAB and Interactive Data Language (IDL). The access to system is through our university course management website, via proper identification. The access is open to all students or users enrolled in the renewable energy and sustainability courses. 


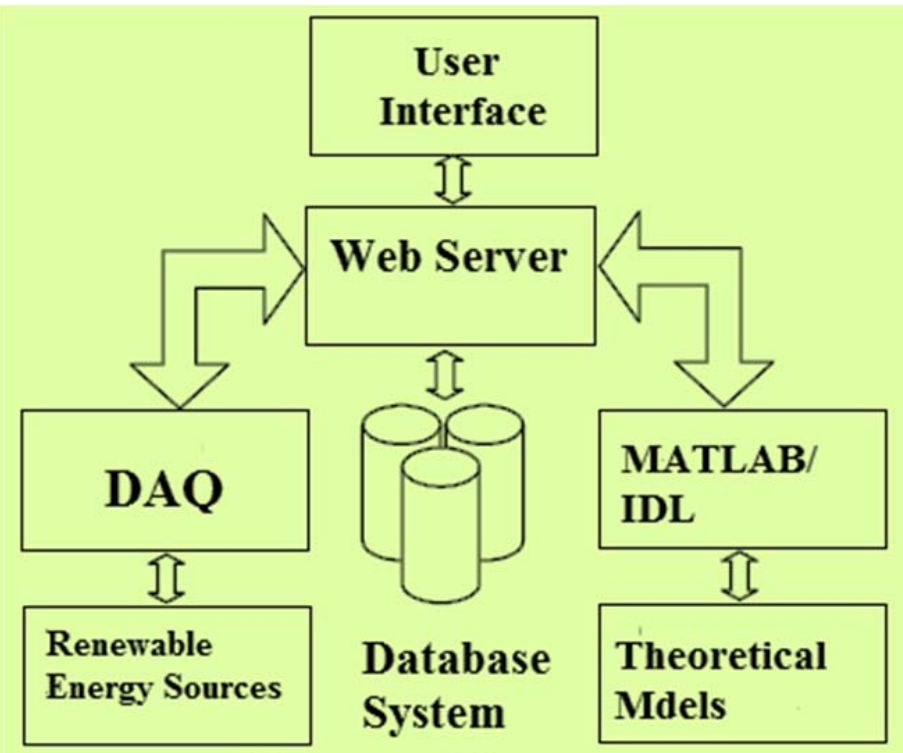

Figure 1 Architecture of the system

An important part of the system is represented by software development. Software development is based on: a) data acquisition and conditioning; b) data storage and retrieval; c) remote access by web application; and d) simulation models. The implementation of this software package is conceived as follows: 1) data acquisition, processing and conditioning; 2) data storage and retrieval; 3) remote access through common web applications; and 4) realistic RES simulation models. The system implementation for each module follows the above approach, while the overall system is an open architecture and system, with later additions easy to add and costeffective. The open system's menu is showed in Figure 2.

\section{RenEnergy Virtual Paltform}

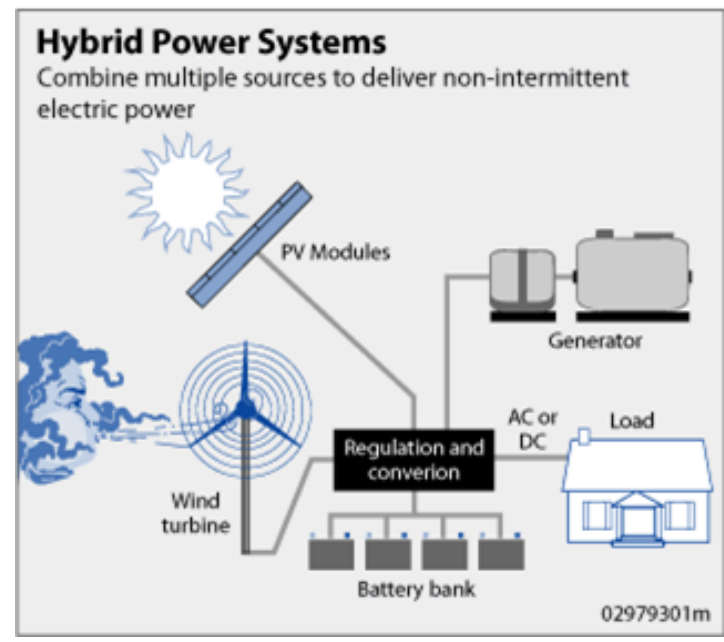

Theoretical Backqround

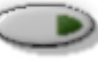

Quizess

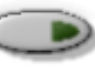

Experiments

Figure 2 Virtual Platform main menu. 


\subsection{Development of laboratory units and e-Learning platform modules}

Modern renewable energy conversion systems are highly complex, incorporating significant processing power and control to perform desired functions and tasks. Teaching courses in renewable energy area is challenging since the field is quite broad and requires significant knowledge in multiple areas of electrical, mechanical, chemical, civil and environmental engineering, and meteorology. These areas include turbine aerodynamics, power electronics, physics, control, electric machines, electrochemistry or structural mechanics. The job of the course provider is often made more difficult because the theoretical analysis of the topics is particularly hard to comprehend without experimental observations. Thus, an effective renewable energy course should contain hands-on design and laboratory in addition to the study of the theory ${ }^{23-36}$. The establishment of the renewable energy laboratory has been based on the following goal: creating a motivating environment for the practice of renewable energy and conventional energy conversion systems. The planned activities, during this project consisted of steps involved in realizing the perceived structure of the virtual laboratory and the e-Learning support platform for renewable energy courses, consist of the design, implementation and testing of the laboratory units, update, reorganize and adapt course materials in the alignment with eLearning requirements.

There are two principal features of the e-learning platform: a) the delivery of information and b) checking of the training results. With the server client structure, the e-Learning platform remains an open system for implementing new information in the future. The information study area is adaptive to the user and the teaching contents are listed in a tree structure, which enables easier orientation of the student during the studying. The control and guidance of the students through the teaching contents will be realized using Petri Nets [6-8]. The bases for the realization of our system the Unified Laboratory for Research, Education and Training of Renewable Energy, Sustainability, and Energy Efficiency (RenSEE-M) are theoretical scenarios based on the existing lectures, supported with the results of the research done by the instructors in the areas of renewable energy and energy conversion, or results published in the literature. The RenSEE-M system was realized as a set of five modules. All the modules are available from the main menu of the RenSEE-M. Each module will have a specific start page, where students become familiar with the main topics that the particular module includes and with the contact person in case of problems during studying. The modules are divided into three parts: basic principles, system technology, and laboratory unit manual. The imparted knowledge are divided into two parts: the first part is the basic knowledge constructed mainly as small text blocks, joined with figures, tables, graphics, animations and simulations realized in MATLAB/Simulink, IDL and LabVIEW. The second part is the deepened knowledge, additional contents of teaching, and Internet links. The teaching part ends with a special test. The tests are realized as a set of multiple choice questions and calculation tasks for testing the acquired knowledge during the course. During the test, the students are denied access to the teaching modules by the control system using the Petri Network. After completing the test, students are allowed to access the laboratory manual.

The laboratory structure and experiments are designed: 1) to reinforce and support the lecturebased courses; 2) to emphasize the importance of corroborating the results of experimentation, measurements, and data analysis; 3) to expose the students to renewable energy technologies, 
characteristics, performances and principles of renewable energy systems. To achieve the above purpose, the laboratory experiments will be divided into two levels: Level I: Virtual Laboratory of Renewable energy Sources; and Level II; the e-Learning Support Platform. The virtual renewable energy laboratory consisting of five emulators facilitate students' acquisition of deep insight into the complex and dynamic interactions of system parameters. A high degree of interactivity should be provided and the students should have the possibility to investigate the causal relation between different states of the system under study. It should be accessible, independent of time and place. Moreover, the renewable energy source models are posted with their simulation under different operating conditions. It is expected that students will be motivated to study and analyze these systems in more detail, so as to become skilled in designing and component layout of such systems. Thereby, the interactive applets show real time simulations for several basic topologies with the flexibility to change the input parameters and observe the output waveforms, correspondingly. The renewable energy sources to be developed for this virtual and remote access laboratory are as follows: 1) Wind Turbine Emulator; 2) PV System Emulator; 3) Fuel Cell Simulator; 4) Solar-thermal Emulator and 5) Battery Bank Emulator.

Each module, with the exception of first one is divided into three parts: basic principles, system technology, and a laboratory manual. All the modules will be available from the main menu of the RenSEE-M. The modules contain the same structure, enabling the student to easily follow the studying materials. Our first goal in the developing of these modules is to capture the attention and then to encourage the interest of the student. To achieve this goal a lot of attention will be paid to construct clear and straightforward ways to introduced teaching concepts, by using animations, simulations and videos. Each module will have a specific start page, where students become familiar with the main topics that the particular module includes and with the contact person in case of problems during studying. The imparted knowledge is divided into two parts: the basic knowledge constructed mainly as small text blocks, joined with figures, diagrams, tables, graphics, animations and simulations realized in MATLB/Simulink, IDL and Maple. The second part is deepened knowledge, including additional contents of teaching, and useful links. The teaching part ends with a test, realized as a set of multiple choice questions and calculation tasks for verifying the reached knowledge. During the test, the students are denied access to the teaching materials by a Petri Net system. The test it to be passed with maximum two attempts. The RenSEE-M begins with a specific start page in which all possible commands and exercise tasks are exemplified. If some problems or questions arise, during the learning sessions, the tutor can be informed via e-mail. Last but not least, to allow teamwork among students some virtual seminars are included at the end of each virtual lecture and they are meant as a final report.

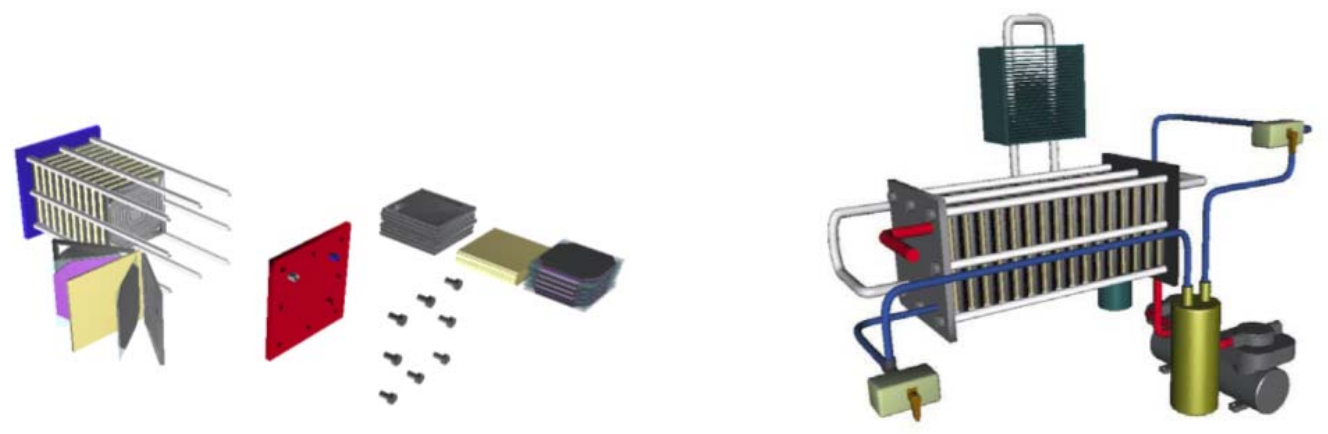

Figure 3: 3-D Fuel Cell Model Assembly 
One of the most innovative features of this project component is the inclusion, in each module of 3-D virtual unit of either a part or the complete renewable energy source or conversion system. The most important geometric features will be developed to represent the renewable energy system. For example, in the 3-D fuel cells module each component is modeled separately, one accurate copy of each element and then integrated into a main file. As one can see in Figure 3 are showing the elements of a fuel cell stack, as well as the system assembly. The most important geometric surfaces are modeled to represent the fuel cell. Each component is modeled separately and then integrated in the main file. The textures, colors and illumination for each element are carefully chosen to create life-like textures for all elements in terms of form bodywork, colors and position. Each component of a 3-D virtual unit is either a part or a complete fuel cell system. The system components can be observed from different visual points, which offer the best possibilities to become familiar with the system assembly. This is also one of our project goals. The students also have the possibility to dismantle the entire system, in this way to learn the basic functions of each part with no need to have a real fuel cell stack. The content of each module is available to the students on demand, which is an important aspect of effective teaching. Moreover, the students will be able to measure and control the function of every element and so to determine the system performances. The integrated measurement system will compile an inspection sheet with the measured parameters.

\subsection{Virtual Platform/e-Learning System Components}

The Emulator of Wind Turbine: The wind turbine emulator (WTE) is designed and implemented considering different requirements from the development and test of control strategy. The WTE is based on a DSP system and a DC motor. The WTE can accurately reproduce the characteristics and performances of the actual wind turbine. The experiment involves: the output torque and power, lift coefficient and efficiency estimates, optimum operation under varying wind conditions, generator power output.

RenEnergy Virtual Paltform
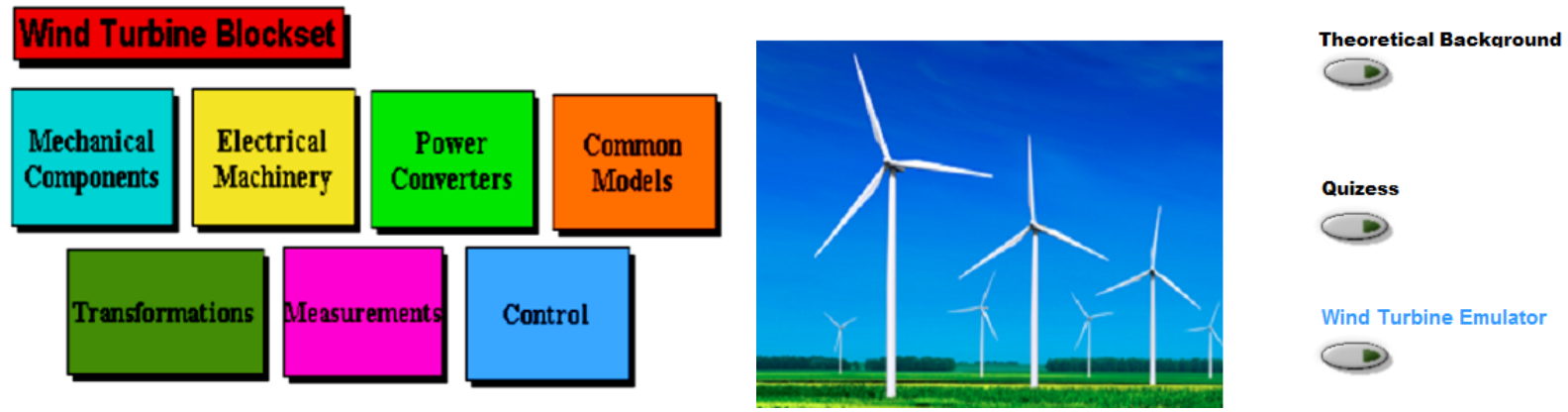

Figure 4 Wind Turbine Block Diagram and Emulator Menu

PV System Emulator: The model of the photovoltaic (PV) array using basic circuit equations of the solar cells including the effects of solar irradiation and temperature changes. PV arrays are built up with series-parallel combinations of the solar cells, scaling up the output of a limited number of PV actual solar cells. A FPGA implementation is proposed for this simulator. The PV simulator is tested and operated using a directly coupled DC load as well as AC load via an inverter. The experiment involves: I-V characteristics of PV, open-circuit voltage, short-circuit 
current, power output vs. insulation, and meteorological parameters, tracking system performances. The emulator was implemented in MATLAB/Simulink and the theoretical model, and data acquisition in IDL and Maple. Figure 5 is showing the Simulink diagram of ths PV emulator.
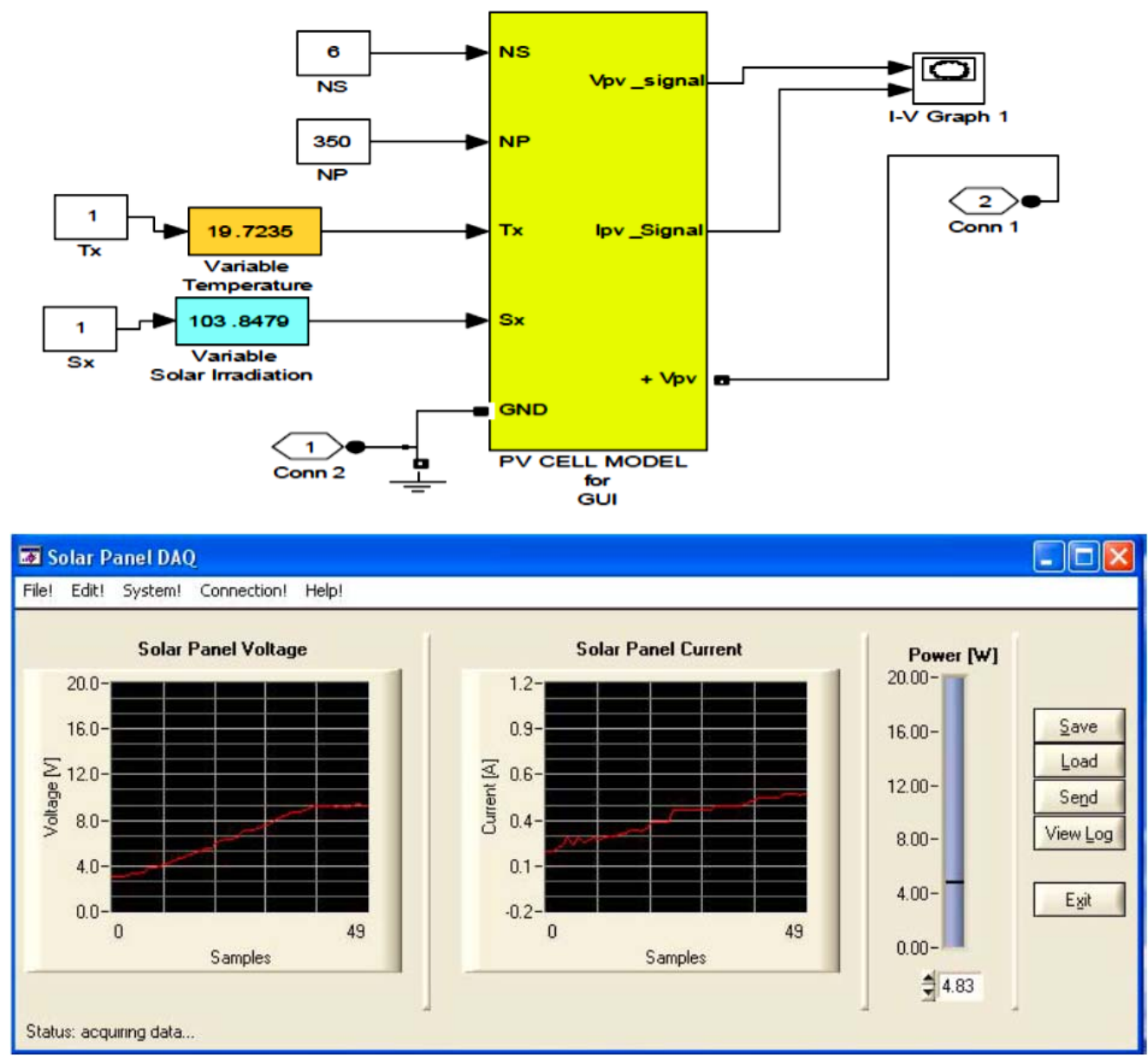

Figure 5 Simulink model of PV array with input and output parameters (measurement window).

Fuel Cell Simulator: The proposed fuel cell simulator emulates the electrical dynamic behavior of the of a fuel cell (FC) stack. This is achieved by controlling a fast dynamic a near time optimal Switching Mode Power Supply (SMPS), representing the dynamic behavior of the FC is generated using a single low cost FC or a FC model that are scaled up to emulate the FC stack. The FC simulator includes also a SMPS control, designed to cope the required dynamic characteristics, the control are network bus interface, and a PC based monitoring and analysis. The experiment involves: fuel cell power and Faraday efficiency, open circuit voltage, power curve, $\mathbf{I}$-V characteristics. The FC emulator panel with the characteristics diagram and input parameters is shown in Figure 6 


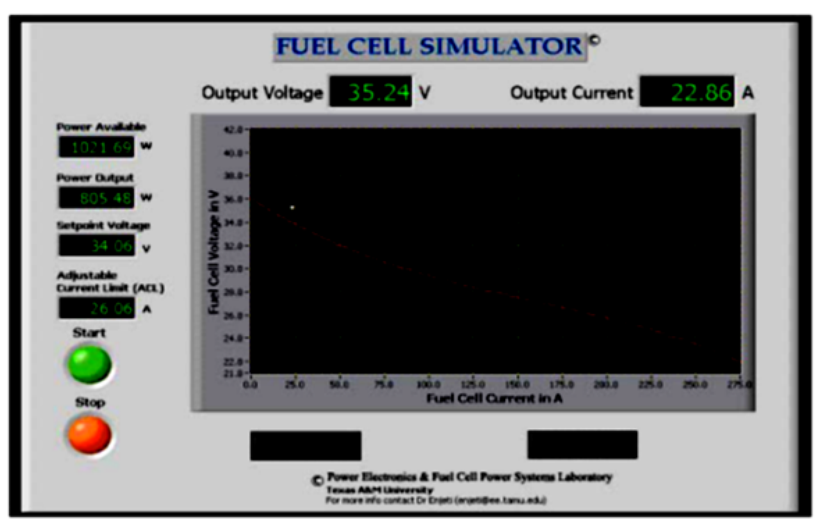

Figure 6 FC characteristics and input panel.

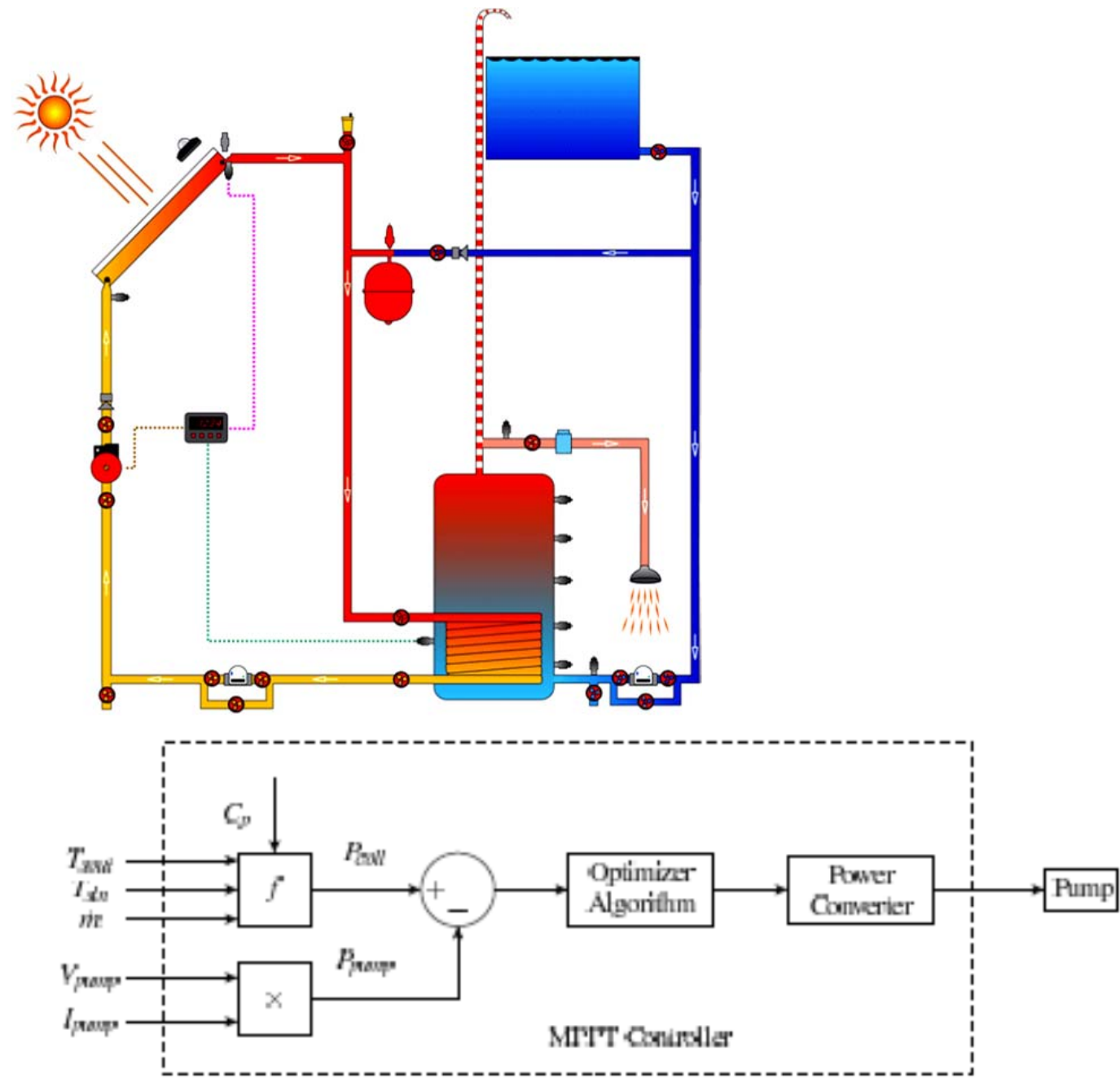

Figure 7 Solar thermal emulator and control scheme diagrams

Solar-thermal Emulator: The solar-thermal energy emulator will comprise flat-plate solar collectors located on ET building, an insulated thermal storage tank located in the solar energy laboratory and other auxiliary equipment and accessories. It is also equipped with 
instrumentation, control and monitoring equipment. The installed hard- and software will include features for controlling external devices, responding to events, processing data, and exchanging information with other applications The experiment involves: temperature and solar radiation measurements, flow rate, collector efficiency and perforamnces. Figure 7 is showing the overall diagrams of the solar-thermal emulator and system control schemes.

Battery Emulator: A programmable power supply that emulates the behavior of a battery will be developed. It measures the current load, calls a battery simulation program to compute the voltage in real time, and controls a linear regulator to mimic the voltage output of a battery. This instrument enables validation of battery power optimization techniques with accurate, controllable, reproducible results. It supports training mode with actual batteries. Involved experiments: battery charging and discharging characteristics, I-V characteristics, power and efficiency

\section{Assessment and Evaluation}

The project objectives and a set of expected and measurable outcomes were used for the evaluation of the project. First, the completeness of the experimental units and e-Learning modules will be assessed. Testing and improvement of the laboratory components and of the emulators including beta-testing and pilot testing for online and remote operation was performed using focus student and instructors groups using seminar format. The developed teaching materials were evaluated by detailed surveys at the end of each quarter. The surveys will evaluate the experimental units and e-Learning modules in terms of the following items:

1) Lab manual: Is the theory presented clearly? Are the methods and procedures well explained?

2) Emulator: Is the emulator easy to use? Is the emulator performance satisfactory?

3) e-Learning module: Is the theory presented helpful? Does the 3-D virtual model show all necessary features?

4) Overall evaluation of the teaching material: Does the teaching materials help you to understand renewable energy systems? Please include your suggestions for improvement.

The laboratory units and e-Learning platform modules will be evaluated by the instructors and TAs as well. The faculty members who participate in testing will be also asked to provide feedback about the developed materials. Their feedback and student surveys were carefully reviewed and proper modifications were made to the emulators and e-Learning modules to improve our e-Learning platform. On a scale from 1 to 5 the student feedback and evaluations on average for two years of using the virtual platform was about 4.60.

The e-learning instructional design is another essential component of learning. Questions addressed to this issue show a good general valuation. The learners/students are aware of learning objectives as they are using the virtual learning environment, and they felt actively involved in the learning process (based on the results of each survey feedback), which is in agreement with its decision to register in the course. The students feel very comfortable learning at its own pace but not so much deciding in what order to learn. It is very plausible that, while the course materials and virtual lab are available at any time, the sequential presentation of some of the scientific content of the modules limit in what order the modules could be completed. The 
tasks to complete each module are clearly stated and the perceived interactivity of the course and experiments reflects that the choices that students make are meaningful and not just not for the sake of making choices.

However, in general, the responses amongst the surveyed groups (students, graduate students (TA) and instructors) showed little divergence. With respect to the graphics, the scores were more demanding, perhaps as a result of comparisons with the quality of graphics found in in many common electronic devices such as mobile phones. This is one of the areas for future improvements, because the graphics and user interface may strongly affect the motivation to use the program. Another area that requires improvement, but could increase the complexity of the calculations and therefore slow down the simulations, is the accuracy of the data obtained for certain models of complex systems such as power plants at high temperature. In addition to the continuous improvement of the application based on information collected from users, especially those aspects that can cause fatal errors and hinder the use of the application, a series of additional surveys will be conducted at the end of the school year to assess the degree of satisfaction with these tools. These additional surveys will be performed to obtain a broader perspective, collect all suggestions for improvements that may be incorporated in later versions and assess the impact of the RenSEE-M Lab implementation on students' academic results.

\section{Conclusions and Future Work}

Teaching renewable energies methodologies accompanied by real system's data increased the comfort, competitiveness, and confidence of the students not only qualitatively, but also quantitatively. It was also observed a positive impact on student's simulation skills.

The design experience develops the students' lifelong learning skills, self-evaluations, selfdiscovery, and peer instruction in the design's creation, critique, and justification. Students learn to understand the manufacturer data sheets, application notes, and technical manuals and component specifications. The experience of teamwork, prototype design and test, which would be difficult to complete individually, gives the students a sense of satisfaction and accomplishment that is often lacking in many engineering courses, not including projects. Furthermore, the design experience motivates student learning and develops skills required in industry. The students were able to make satisfactory estimations and calculations of these projects. Their results reflect that they have understood well all the basic ingredients of the modeling techniques and design of the renewable energy systems. They were also very pleased with the approach used to teach them. Our experience with the incorporation of renewable energy topics in the senior project design courses demonstrated that the abstract knowledge acquired by the students during their first three years of studies was put into practice. The students in these virtual laboratory units also gained extensive knowledge of power electronics, generator and mechanical components of renewable energy sources, their characteristics, environmental and structural constraints, separating different aspects of the project, such as generator or converter type, its parameters and characteristics, and what are the final outputs and its relationship to the load, etc.

The key element to the success was the interdisciplinary team work and the efforts of the faculty to continually instruct the students on the completion of their projects. The lessons learned from 
this type of projects lead us to believe that they are very attractive and favorable for students. Finally, they may represent one of the ways to enhance engineering education in our college.

\section{References}

1. National Renewable Energy Laboratory, "Learning about Renewable Energy”, http://www.nrel.gov/learning/, Accessed: 19 January 2009.

2. U.S Senate Committee on Energy and Natural

Resources,http://energy.senate.gov/news/dem_release.cfm?id=221179

3. Annual Energy Outlook 2006 with Projections to 2030 (Early Release) - Overview.(December 2005).

Energy Information Administration, U.S. Department of Energy, from

http://www.eia.doe.gov/oiaf/aeo/table1.html.

4. On The Road to Energy Security - Implementing A Comprehensive Energy Strategy: A Status Report. (2006). U.S. Department of Energy, Retrieved September 24, 2006, from http://www.energy.gov/about/EPAct.htm.

5. K.A. Rosentrater, K. A. \& Al-Kalaani, Y., Renewable energy alternatives - a growing opportunity for engineering and technology education. The Technology Interface, 6(1), 2006,

6. P. Jennings, New directions in renewable energy education. International Journal of Renewable Energy, 34, 435-439, 2009.

7. G.T. Heydt and V. Vittal, “Feeding Our Profession”, IEEE Power \& Energy Vol. 1(1), 2003.

8. U.S Energy Information Administration, Renewable Energy Annual 2002.

9. ABET, “Criteria for Accrediting Engineering Programs”, ABET, Inc., 2010.

10. Currin, T., "The Capstone Design Course and Its failure to serve as an effective outcome assessment tool”, Proceedings of the 2002 ASEE Annual Conference and Exposition.

11. Liaw, S., T. Huang, and G. Chen, "Surveying instructor and learner attitudes toward e-learning", Comput. Educ., vol. 49, no. 4, pp. 1066-1080, 2007.

12. Pecen R., Timmerman M., “ A Hands-on Renewable Energy Based Laboratory for Power Quality Education”, Session 1333, Proceedings of the 2001 ASEE Annual Conference and Exposition.

13. Davis K.C., "Enhancing Communication Skills in Senior Design Capstone Projects”, Proceedings of the 2002 ASEE Annual Conference and Exposition.

14. Colace, F., M.De Santo, and A. Pietrosanto, "Work in Progress - Virtual Lab for Electronic Engineering Curricula”, 34 ${ }^{\text {th }}$ ASEE/IEEE Frontiers in Education Conference, October 20 - 23, 2004, Savannah, GA.

15. R. M. Ford, and C. S. Coulston, Design for Electrical and Computer Engineers, McGraw Hill, 2008.

16. E. O’Neill-Carrillo, E. Marrero, and A. Irrizarry-Rivera, “Integrated Experiences in Power

Engineering courses” 9th International Conf. on Engineering Education, San Juan, PR, July 23-28, 2006. TD4:7-11.

17. E. I. Ortiz-Rivera, and M. J. Castro-Sitiriche, "Work in Progress - Integration of Hands-OnLaboratory Experience of Power Electronics and Renewable Energy Applications”, 39th ASEE/IEEE Frontiers in Education Conference, October 18 - 21, 2009, San Antonio, TX, (CD Proceedings) 18. E. Koutroulis, K. Kalaitzakis, N.C. Voulgaris, "Development of a Microcontroller-Based, Photovoltaic Maximum Power Point Tracking Control System,” IEEE trans. on Power Electronics, Vol. 16, pp 46-54, Jan. 2001.

19. J. Van den Keybus, B. Bolsens, K. De Brabandere, J. Driesen, "Using a fully digital rapid prototype platform in grid-coupled power electronics applications,” presented at the 9th IEEE Conference on Computers and Power Electronics (COMPEL 2004), Champaign-Urbana, USA, 2004.

20. M. H. Nehrir, “A course on alternative energy wind/PV/fuel cell power generation”, 2006 IEEE Power Engine ering Society Meeting, Montreal, Canada, 2006. 
21. S. Santoso and W.M. Grady, "Developing an Upper-Level Undergraduate Course on Renewable Energy and Power Systems,” Proceedings, 2005 IEEE PES General Meeting, San Francisco, CA, June 12-16.

22. Patel. R. M., Wind and Solar Power Systems, CRC Press, 1999.

23. R.G. Belu R.G., Design and Development of Simulation System for Renewable Energy Laboratory, 2010 ASEEE Conference \& Exposition, June 20 - 23, Louisville, Kentucky (CD Proceedings).

24. R.G. Belu and D. Koracin, E-learning Platform for Renewable Energy Sources, 2010 ASEEE Conference \& Exposition, June 20 - 23, Louisville, Kentucky (CD Proceedings)

25. R.G. Belu, A Project-based Power Electronics Course with an Increased Content of Renewable Energy Applications, June 14-17, 2009 Annual ASEE Conference and Exposition, Austin, Texas (CD Proceedings).

26. R.G. Belu and A.C. Belu, A DecisionSupport Software Application for Design of Hybrid Solar-Wind Power Systems- as Teaching-Aid, 2007Annual ASEE Conference, and Exposition, Honolulu, Hawaii (CD Proceedings).

27. R. Ehrlich, Stimulating Renewable Energy Education in the U.S. and Globally, Bulletin of the American Physical Society, APS April Meeting 2010, Volume 55, Number 1

28. L. Bin, Integrating Renewable Energy Education Into National High Educational System, Proceedings of ISES World Congress (Vol. I - Vol. V) Solar Energy and Human Settlement, 2007, pp. 29. L. J. Issing, G. Stärk, "Studieren mit Multimedia und Internet. Medien der Wissenschaft", vol. 16, Waxmann Verlag, 2002.

30. B. Hadzi-Kostova, Z. Styczynski, "Teaching Renewable Energy using Multimedia", PSCE 2004, New York, October 10.-13., 2004.

31. B. Hadzi-Kostova, J. Haubrock, A. Lebioda, A. Orths, Z. Styczynski, Teaching Renewable Energy Using E-Learning System RegEn-M (Renewable Energy Multimedial) ", ED-MEDIA, Lugano, Switzerland, June 21.-26., 2004.

32. T. Dana-Picard, I. Kidron, M. Komar, J. Steiner, J., "ICT-aided engineering courses: a multi-cmpus course management”, European Journal of Engineering Education, Vol. 31, No. 4, 2006, pp. 373-381. 33. N. Heap, KL Kear, C. Bissell, “An overview of ICT-based assessment for engineering education”, European Journal of Engineering Education, Vol. 29, No. 2, 2004, pp. 241-250.

34. A.S. Blicblau, A.S., "Online delivery management for teaching and learning”, European Journal of Engineering Education, Vol. 31, No. 2, 2006, pp. 237-246.

35. C. Belardinelli, Bl"umel, E., M“uller, G., Schenk, M, Making the virtual more real: research at the Fraunhofer IFF Virtual Development and Training Centre. Journal Cognitive Processing, S217-S224 (2008) ISSN 9217-224

36. J. V. Nickerson, J. E. Corter, S. K. Esche, C. Chassapis. A model for evaluating the effectiveness of remote engineering laboratories and simulations in education. Computers \& Education, Vol. 49, 3,pp. 708-725, November 2007. 